\title{
Dose response of dexmedetomidine-induced resistance to hypoxia in mice
}

\author{
WANYING PAN ${ }^{1}$, XIAOXIAO HUA ${ }^{1}$, YUETING WANG ${ }^{1}$, RUIXIAN GUO ${ }^{2}$, JINGFU CHEN ${ }^{3}$ and LIQIU MO ${ }^{1}$ \\ ${ }^{1}$ Department of Anesthesiology, The First Affiliated Hospital; ${ }^{2}$ Department of Physiology, \\ Zhongshan Medical College; ${ }^{3}$ Department of Cardiovasology and Cardiac Care Unit, \\ Huangpu Division of The First Affiliated Hospital, Sun Yat-sen University, Guangzhou, Guangdong 510080, P.R. China
}

Received July 12, 2015; Accepted June 9, 2016

DOI: $10.3892 / \mathrm{mmr} .2016 .5588$

\begin{abstract}
Tolerance to hypoxia can be induced by reducing oxygen consumption. Dexmedetomidine (DEX) decreases locomotor activity and induces bradycardia and hypothermia in mice. The present study examined the hypothesis that DEX improves hypoxia tolerance in mice. Adult mice received an intraperitoneal injection of 1, 5, 10, 20, 40, 80, 160 or $320 \mu \mathrm{g} / \mathrm{kg}$ DEX, $20 \mathrm{mg} / \mathrm{kg}$ propranolol or saline. Acute hypoxic conditions were induced by placing the mice in a limited enclosed container with soda lime. Core body temperature (CBT) and heart rate (HR) were measured prior to and 30 min after drug administration. Survival time was monitored in the sealed container. Survival times (mean \pm standard deviation) of mice in the saline, $1,5,10,20,40,80,160$ and $320 \mu \mathrm{g} / \mathrm{kg} \mathrm{DEX}$, and the $20 \mathrm{mg} / \mathrm{kg}$ propranolol groups were $22.4 \pm 1.1,23.4 \pm 1.1$, $26.0 \pm 0.9,36.9 \pm 5.2,42.4 \pm 2.9,43.2 \pm 2.3,58.2 \pm 4.2,80.5 \pm 4.0$, $79.2 \pm 6.0$, and $38.2 \pm 2.8 \mathrm{~min}$, respectively. Pretreatment with propranolol and $10,20,40,80,160$ or $320 \mu \mathrm{g} / \mathrm{kg} \mathrm{DEX}$, but not 1 or $5 \mu \mathrm{g} / \mathrm{kg}$, significantly prolonged survival time compared with saline-injected mice $(\mathrm{P}<0.05$ or $\mathrm{P}<0.01)$. CBT and HR decreased in a similar manner. The correlation coefficients between survival time and CBT, and survival time and HR were -0.802 and -0.726 , respectively. Thus, DEX dose-dependently enhances hypoxia tolerance in mice. In conclusion, it is suggested that DEX may be used in clinical practice as a novel protective agent for organs and tissues during hypoxic injury.
\end{abstract}

\section{Introduction}

Oxygen metabolism is a fundamental requirement for life. However, hypoxia is one of the most common causes of injury, leading to morbidity and mortality in various pathological

Correspondence to: Professor Liqiu Mo, Department of Anesthesiology, The First Affiliated Hospital, Sun Yat-sen University, 74 Zhongshan 2nd Road, Guangzhou, Guangdong 510080, P.R. China

E-mail: mlqiu11220@126.com

Key words: dexmedetomidine, hypoxia, hypothermia conditions, including anesthetic accidents, shock, myocardial infarction, stroke, drowning, sleep apnea and acute respiratory distress syndrome. Hypoxia results in decreased aerobic energy production and increased production of damaging free radicals that can lead to cell injury and death. Thus, hypoxia is a clinically important issue. Tolerance to hypoxia is inherited in some species, such as estivating and hibernating animals, and enables survival for long periods even under pure nitrogen/no oxygen conditions. Species that estivate or hibernate enter steady-state torpor and are not hypoxic despite tenfold or greater decreases in heart and respiratory rates, accompanied by hypothermia $(1,2)$. A hypometabolic state is central to hypoxia tolerance and is characterized by reduced oxygen consumption (3). Notably, certain toxic gases, including hydrogen disulfide (4) and carbon monoxide (5), can induce a suspended animation-like state and significantly enhance tolerance to hypoxia in mice and Caenorhabditis elegans, respectively. Previous studies have reported that several small molecules, such as sevoflurane $(6,7)$ and magnesium sulfate (8), boost hypoxia/ischemic tolerance in the brain. However, these agents have limited use due to their controversial neurotoxicity (9) and cardiodepressive effects at high serum concentrations (10).

Dexmedetomidine (DEX) is a highly selective $\alpha_{2}$ adrenoreceptor agonist that is widely used as an anesthetic adjuvant, primarily for sedation, anxiolysis, sympatholysis, and analgesia (11). Increasing evidence suggests that DEX protects against ischemia-reperfusion injury, including neuroprotection (12-14), cardioprotection $(15,16)$, renoprotection $(17,18)$, and intestinal protection $(19,20)$. Notably, DEX has also been previously demonstrated to markedly reduce locomotor activity, heart rate (HR), respiratory rate, and core body temperature (CBT) in mice $(21,22)$, which appear to be in a suspended animation-like state following DEX administration. However, whether DEX improves hypoxia tolerance in mice remains unknown. The current study aimed to elucidate the effects of different doses of DEX on the survival time of mice under acute asphyxiating conditions.

\section{Materials and methods}

Animals. A total of 68 male Kunming strain mice (weight, $36 \pm 3 \mathrm{~g}$; age, 8-12 weeks) were used. All animals were 
housed under a 12-h light-dark cycle in a temperature and humidity-controlled environment with unlimited access to water and food.

This study was approved by the ethics committee of The First Affiliated Hospital, Sun Yat-sen University (Guangzhou, China) and was performed in according to the National Institutes of Health guidelines for use of experimental animals. The experiments were conducted between 10:00 and 17:30 h. The minimum number of animals was used in each experiment and all efforts were made to minimize animal suffering.

Experimental groups and procedures. The mice were randomly allocated into 10 groups following a 7-day acclimation, with each group contained 6-7 mice/group. The groups received a single dose of $1,5,10,20,40,80,160$ or $320 \mu \mathrm{g} / \mathrm{kg}$ DEX-HCl (Jiangsu Hengrui Medicine Co., Ltd., Jiangsu, China), $20 \mathrm{mg} / \mathrm{kg}$ propranolol-HCl (Sigma-Aldrich, St. Louis, MO, USA) as a positive control or $0.9 \%$ saline by intraperitoneal injection.

Weight, CBT, and HR of the mice were measured prior to injection of the drugs or saline. CBT and HR were rerecorded $30 \mathrm{~min}$ after the injections, and survival time measurement was initiated.

CBT measurement. CBTs were recorded using a rectal probe connected to a digital thermometer. The probe was inserted $2 \mathrm{~cm}$ inside the anal sphincter and the CBT of each animal was recorded twice, immediately before and $30 \mathrm{~min}$ after the drug administration.

Heart rate measurement. HRs were measured noninvasively with a tail-artery sphygmomanometer (Softron Biotechnology Co., Ltd., Beijing, Chain). The HR of each mouse was recorded twice, immediately before and $30 \mathrm{~min}$ after the drug injections.

Survival time testing. Hypoxic conditions were induced as previously described by Shen et al (23). Briefly, the mice were placed into a $250-\mathrm{ml}$ sealed bottle (one mouse/bottle) containing $15 \mathrm{~g}$ soda lime (Mingxiang Biotechnology, Weihai, China), and survival time was determined as the time of the last breath as an indication of death.

Statistical analysis. Parametric data are presented as the means \pm standard deviation and analyzed by one-way repeated-measures analysis of variance followed by the least significant difference test. Survival times were analyzed using the Kaplan-Meier method and differences between the groups were identified using the log-rank test. Correlations between variables were estimated using Pearson's correlation coefficient analysis. All statistical analyses were performed using SPSS software (version. 13.0; SPSS Inc., Chicago, IL, USA). P<0.05 was considered to indicate a statistically significant difference.

\section{Results}

DEX dose-dependently reduces HR in mice. The physiological data collected prior to the experiment are presented in Table I. No significant differences between body weight, CBT and HR values were observed among the groups.

The effect of propranolol and the different doses of DEX on hemodynamics are demonstrated in Fig. 1. The lower DEX

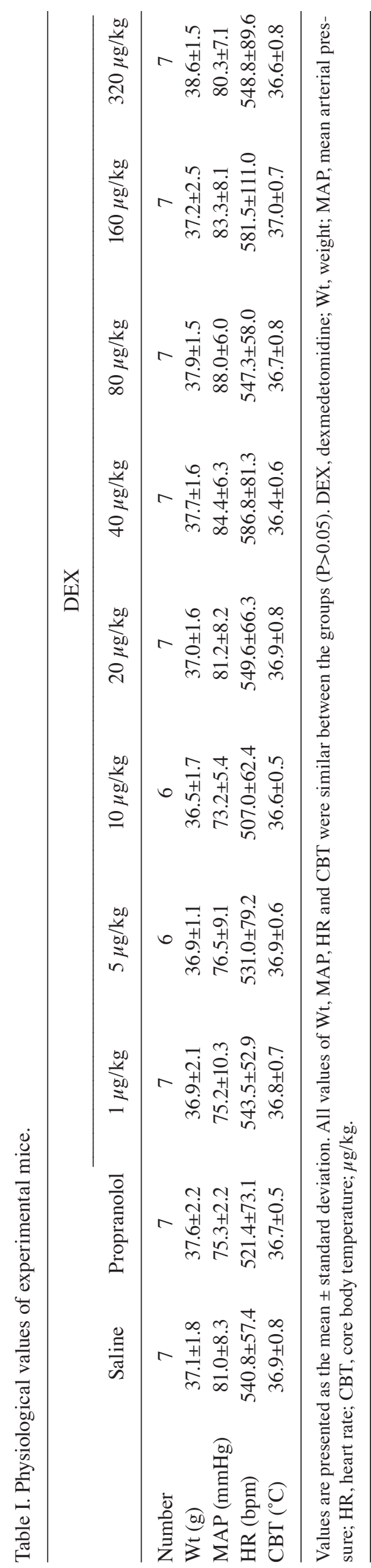



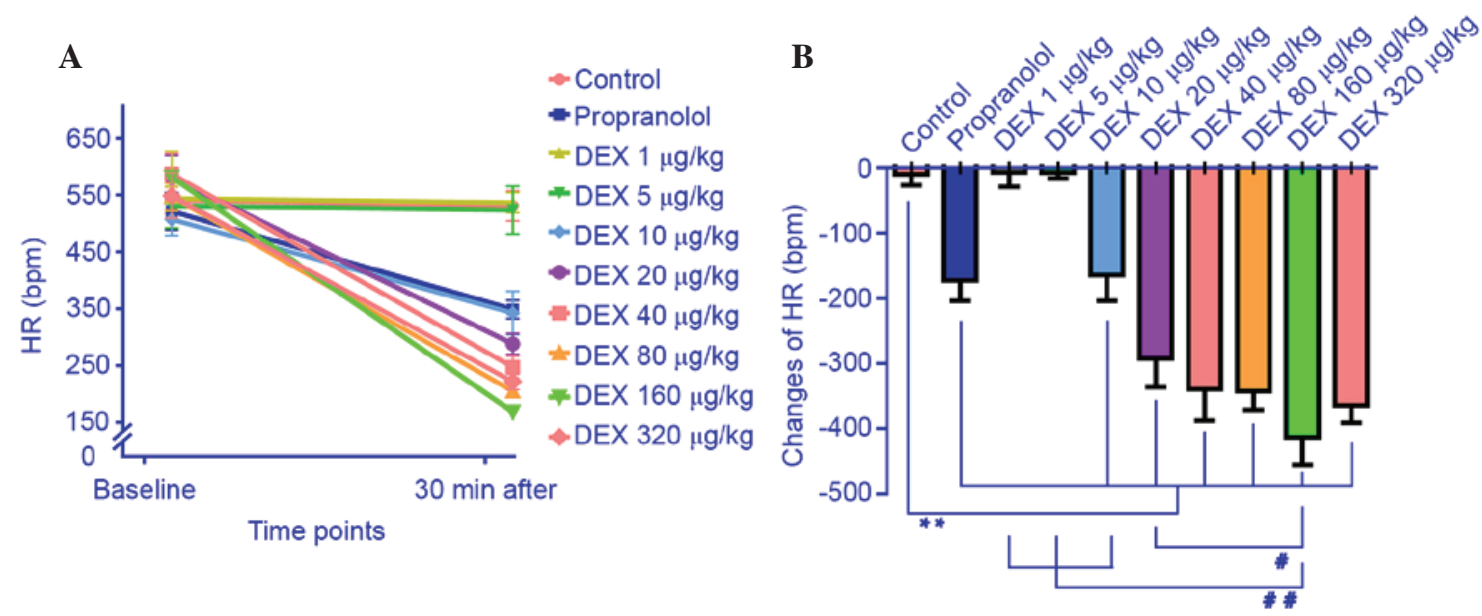

Figure 1. Effects of various DEX dosages and $20 \mathrm{mg} / \mathrm{kg}$ propranolol and saline on HR in mice. (A) HR at baseline and $30 \mathrm{~min}$ after the drug injections. No significant differences were observed among the groups at baseline. The different treatments induced decreases in HR of different magnitudes after 30 min. (B) Changes of HR following treatment with the different drug and dose. ${ }^{* *} \mathrm{P}<0.01$ vs. control group; ${ }^{*} \mathrm{P}<0.05,{ }^{\# \#} \mathrm{P}<0.01160 \mu \mathrm{g} / \mathrm{kg}$ DEX group. DEX, dexmedetomidine; HR, heart rate.
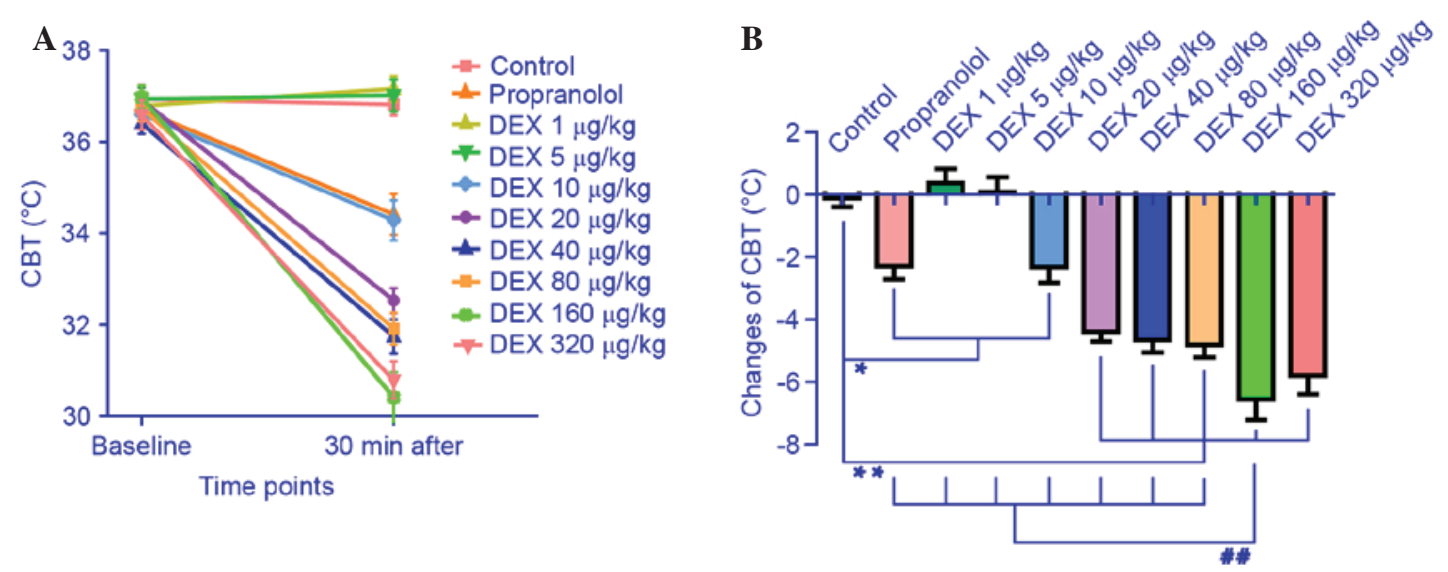

Figure 2. Effects of various DEX dosages and $20 \mathrm{mg} / \mathrm{kg}$ propranolol and saline on CBT in mice. (A) CBT at baseline and 30 min after drug injections. No significant differences were observed among the groups at baseline. The different treatments induced decreases in CBT of different magnitudes after 30 min. (B) Changes of in CBT following treatment with the different drugs and doses. Hypothermia induced by DEX was the most obvious at the $160 \mu \mathrm{g} / \mathrm{kg}$ dose $\left(30.41 \pm 1.45^{\circ} \mathrm{C}\right)$, which was a decrease of $-6.56 \pm 1.62^{\circ} \mathrm{C}$. ${ }^{\prime \prime} \mathrm{P}<0.05,{ }^{* *} \mathrm{P}<0.01$ vs. control group; ${ }^{\sharp \prime} \mathrm{P}<0.01 \mathrm{vs} .160 \mu \mathrm{g} / \mathrm{kg}$ DEX group. DEX, dexmedetomidine; CBT, core body temperature.

doses $(1$ and $5 \mu \mathrm{g} / \mathrm{kg})$ did not significantly affect $\mathrm{HR}(-7.0 \pm 56.4$ and $-7.5 \pm 28.5 \mathrm{bpm}$, respectively) compared with the saline group. However, the higher DEX doses $(10,20,40,80,160$ and $320 \mu \mathrm{g} / \mathrm{kg}$ ) and $20 \mathrm{mg} / \mathrm{kg}$ propranolol significantly reduced the HR values $(342.6 \pm 85.1,288.0 \pm 44.9,247.4 \pm 43.5,209.2 \pm 19.1$, $168.5 \pm 18.0,221.6 \pm 30.4$ and $348.8 \pm 36.4 \mathrm{bpm}$, respectively) compared with the saline group $(\mathrm{P}=0.003,0.000,0.000,0.000$, $0.000,0.000$ and 0.002 , respectively). As the DEX dose was increased further $(10,20,40,80$ and $160 \mu \mathrm{g} / \mathrm{kg})$, HR decreased significantly and reached the minimum level at $160 \mu \mathrm{g} / \mathrm{kg}$ DEX (-413.0 $\pm 108 \mathrm{bpm})$. The HR of mice treated with $320 \mu \mathrm{g}$ $\mathrm{DEX} / \mathrm{kg}$ did not decrease further but was maintained at a low level $(\mathrm{P}=0.09)$ compared with the $160 \mu \mathrm{g} / \mathrm{kg}$ DEX group.

DEX dose-dependently induces hypothermia in mice. The effect of the different DEX doses and propranolol on the CBT of the mice is demonstrated in Fig. 2. The CBT was significantly reduced in the propranolol group $\left(-2.29 \pm 1.04^{\circ} \mathrm{C}\right)$ compared with in the saline group $\left(-0.11 \pm 0.70^{\circ} \mathrm{C} ; \mathrm{P}=0.001\right)$. Mice administered with the lower doses of DEX (1 and $5 \mu \mathrm{g} / \mathrm{kg}$ ) did exhibit a significant decrease in CBT. Notably, compared with the control group, CBT was decreased significantly $(\mathrm{P}=0.456, \mathrm{P}=0.770)$ in mice treated with $\geq 10 \mu \mathrm{g}$ $\mathrm{DEX} / \mathrm{kg}$. Additionally, CBT was reduced to a minimum of $-6.56 \pm 1.62^{\circ} \mathrm{C}$ following administration of $160 \mu \mathrm{g} \mathrm{DEX} / \mathrm{kg}$. Then, compared with the $160 \mu \mathrm{g} / \mathrm{kg}$ group, CBT remained at a low level without a further significant decrease in mice treated with $320 \mu \mathrm{g} / \mathrm{kg}$ DEX $\left(-5.8 \pm 1.44^{\circ} \mathrm{C} ; \mathrm{P}=0.247\right)$.

DEX increases survival time in mice. The effects of DEX, propranolol and saline on survival time are demonstrated in Fig. 3. The survival time of mice in the saline group was $22.4 \pm 2.6 \mathrm{~min}$. No significant effect on survival time was observed following administration with the lower DEX doses $(1 \mu \mathrm{g} / \mathrm{kg}, 23 \pm 2.8 \mathrm{~min} ; 5 \mu \mathrm{g} / \mathrm{kg}, 26.0 \pm 2.3 \mathrm{~min} ; \mathrm{P}=0.607)$ compared with the saline group. However, treatment with the 

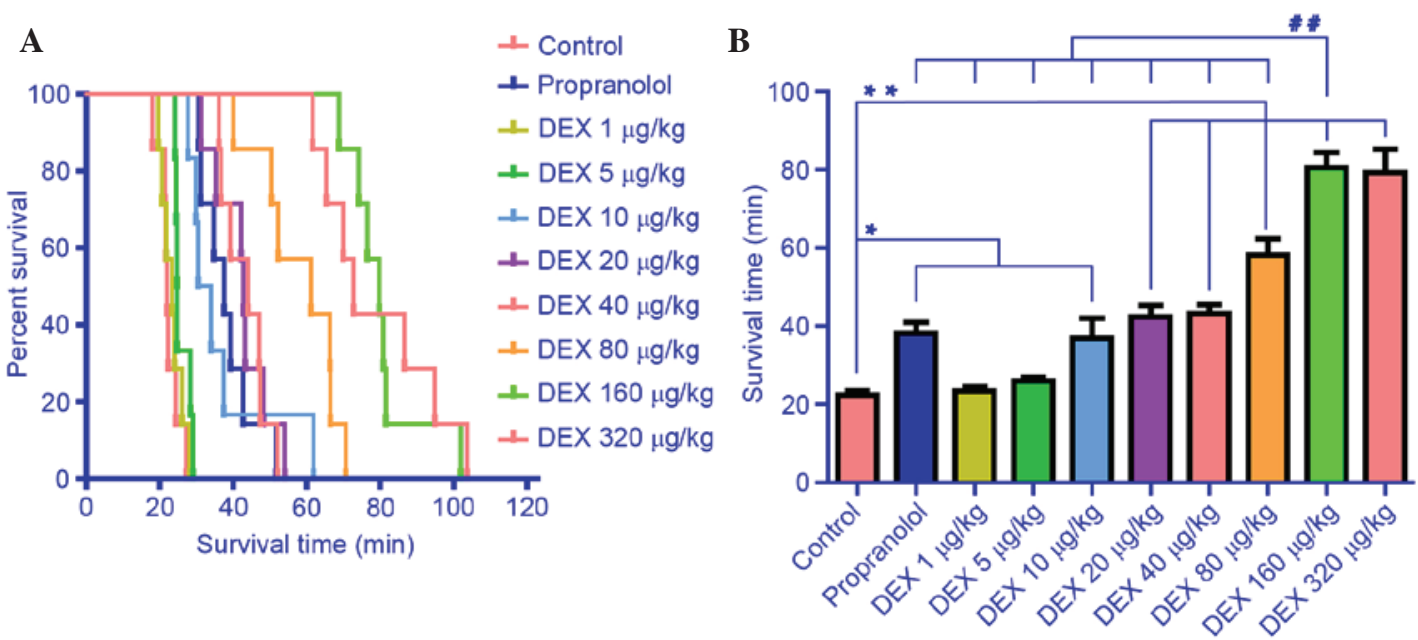

Figure 3. Effects of various DEX dosages and $20 \mathrm{mg} / \mathrm{kg}$ propranolol and saline on survival time in mice. (A) Survival curve. Results were compared using the Kaplan-Meier method and the log-rank test. (B) Survival time is shown in the histogram. Survival time was extended as the DEX dose was increased and reached a maximum at $160 \mu \mathrm{g}$ DEX/kg. ${ }^{*} \mathrm{P}<0.05,{ }^{* * *} \mathrm{P}<0.01$ vs. control group; ${ }^{\# \#} \mathrm{P}<0.01 \mathrm{vs} .160 \mu \mathrm{g} / \mathrm{kg}$ DEX group. DEX, dexmedetomidine.

A

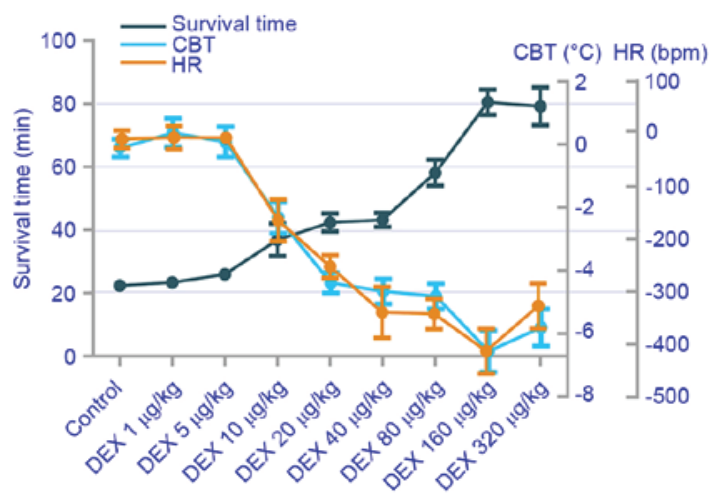

B

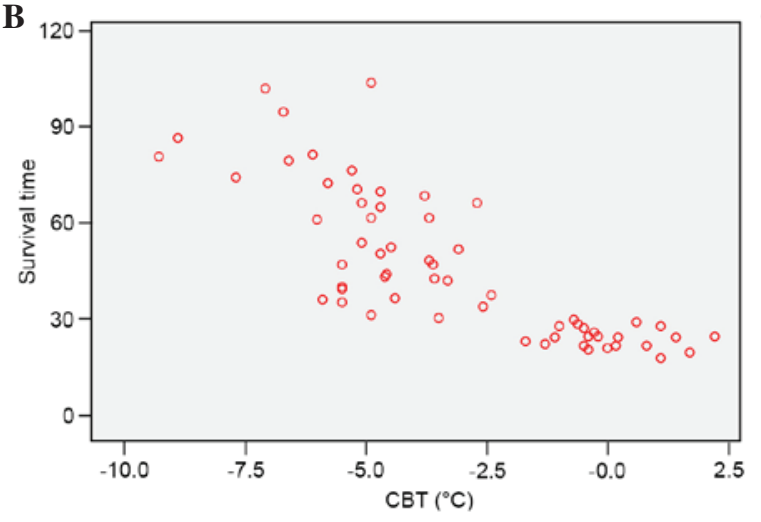

C

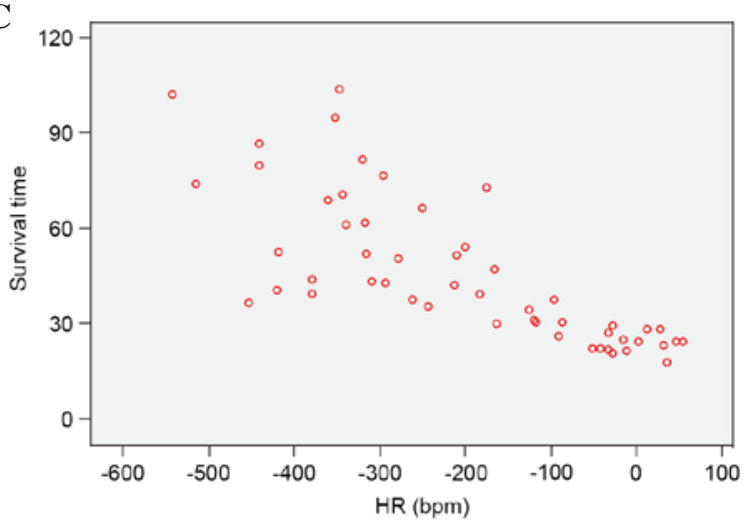

Figure 4. Correlations between CBT and survival time and HR and survival time in mice. (A) Trends in HR, CBT, and survival time after administration of different DEX doses. Survival time depended on reductions in CBT and HR; greater decreases in CBT and HR led to longer survival times. (B) The significant negative correlation $(\mathrm{r}=-0.802)$ between survival time and CBT. $(\mathrm{C})$ The significant negative correlation $(\mathrm{r}=-0.726)$ between survival time and HR. CBT, core body temperature; HR, heart rate; DEX, dexmedetomidine.

higher doses of DEX $(10,20,40,80$ and $160 \mu \mathrm{g} / \mathrm{kg})$ significantly increased survival time in a dose-dependent manner compared with the control group $(\mathrm{P}=0.006,0.000,0.000,0.000$ and 0.000 , respectively). The maximal extension of survival time was $80.5 \pm 9.7 \mathrm{~min}$ at $160 \mu \mathrm{g} \mathrm{DEX} / \mathrm{kg}$, which was $\sim 3.6$ times that of the control group $(\mathrm{P}=0.000)$. Survival time was not extended further following administration of $320 \mu \mathrm{g} / \mathrm{kg}$ DEX $(79.2 \pm 14.7$ $\mathrm{min} ; \mathrm{P}=0.791$ ) compared with the $160 \mu \mathrm{g} / \mathrm{kg}$ group. Survival time of mice treated with $20 \mathrm{mg} / \mathrm{kg}$ propranolol was marginally extended compared with the control group (38.2 $\pm 6.8 \mathrm{~min}$; $\mathrm{P}=0.002$ ), and exerted an equivalent effect compared with 10 , 20 and $40 \mu \mathrm{g} / \mathrm{kg}$ DEX ( $\mathrm{P}=0.792,0.389$ and 0.306$)$.

Correlation analysis. The correlation analysis between survival time and CBT, and survival time and HR, are presented in Fig. 4. Strong negative correlations were detected 
between survival time and CBT ( $\mathrm{r}=-0.802)$, and survival time and HR ( $r=-0.726)$.

\section{Discussion}

Despite recent progress, the main mechanisms underlying DEX-induced multiorgan protection remain poorly understood and require further investigation. The current study demonstrated that DEX dose-dependently improved tolerance to hypoxia in mice, which may partially explain the mechanism. Propranolol is a $\beta$-adrenoreceptor antagonist that effectively extends the survival time of mice under limited oxygen conditions (23). Thus, propranolol was used as a positive control to determine the efficacy of DEX. The results of the present study demonstrate that the lower doses of DEX (1 and $5 \mu \mathrm{g} / \mathrm{kg}$ ) did not significantly extend survival time of the mice, but the higher doses $(10,20,40,80,160$ and $320 \mu \mathrm{g} / \mathrm{kg}$ ) significantly prolonged survival time compared with the control, which peaked at the dose of $160 \mu \mathrm{g} / \mathrm{kg}$ and was 3.6 times longer than that observed in the control group. Furthermore, CBT and HR decreased similarly in response to DEX. Propranolol appeared to have a limited effect on extending survival time and only marginally decreased HR and CBT.

DEX decreases HR in various animals, including rodents and humans $(24,25)$. The hypothermic effects of DEX observed in the present study were consistent with previous reports $(21,22)$, excluding the magnitude of the changes. For example, body temperature decreased by almost $15^{\circ} \mathrm{C}$ in a report by Sallinen et al (22), whereas in the current study the result was closer to $7^{\circ} \mathrm{C}$. It is speculated that multiple factors may be involved in the difference in the magnitude of the decrease in CBT; the time points of the measurements differed in the two studies, the previous study measured body temperature $90 \mathrm{~min}$ after the drug injection, whereas the current study measured CBT 30 min after drug administration. Additionally, a different mouse strains were used in the different studies.

Hypoxia/ischemia is a common clinical condition and is often so critical that treatment must begin immediately to secure homeostasis. Hypoxia/ischemia injury results from an imbalance between oxygen supply and demand. Certain natural phenomena, including hibernation, estivation and a suspended animation-like state, effectively, and markedly reduce oxidative metabolism and oxygen demand of an organism. The current study combined these two events and explored whether these natural phenomena may be induced, such as a suspended animation-like state, to apply clinically for a beneficial effect. DEX is a promising novel type of anesthetic; it causes sedation, hypothermia, bradycardia and decreases the respiration rate, similar to a state of suspended animation. Furthermore, DEX protects organs against ischemia-reperfusion injury (12-20). To the best of our knowledge, no other widely used drugs exhibit these clinically valuable properties.

The hypoxia animal model used in the present study was simple but novel, as it is completely consistent with the clinical pathology of hypoxia, with oxygen decreasing gradually, not immediately. Several potential limitations of this study should be acknowledged. CBT and HR were only measured before and 30 min after drugs administration, and thus, are unsure how these values fluctuated during asphyxia. Further studies are required to probe the mechanisms underlying the significant effects of DEX.

In summary, the current study demonstrated a novel effect for DEX in enhancing tolerance to hypoxia in mice by inducing hypothermia and bradycardia. This finding provides novel insight for the clinical use of DEX in lethal organ hypoxia/ischemia and hypothermia therapies.

\section{Acknowledgements}

This work was supported by the Science and Technology Plan projects of Guangdong Province (2012B031800289).

\section{References}

1. Biorck G, Johansson B and Schmid H: Reactions of hedgehogs, hibernating and non-hibernating, to the inhalation of oxygen, carbon dioxide and nitrogen. Acta Physiol Scand 37: 71-83, 1956.

2. Frerichs KU, Kennedy C, Sokoloff L and Hallenbeck JM: Local cerebral blood flow during hibernation, a model of natural tolerance to 'cerebral ischemia'. J Cereb Blood Flow Metab 14: 193-205, 1994.

3. Ramirez JM, Folkow LP and Blix AS: Hypoxia tolerance in mammals and birds: From the wilderness to the clinic. Annu Rev Physiol 69: 113-143, 2007.

4. Blackstone E, Morrison M and Roth MB: H2S induces a suspended animation-like state in mice. Science 308: 518, 2005.

5. Nystul TG and Roth MB: Carbon monoxide-induced suspended animation protects against hypoxic damage in Caenorhabditis elegans. Proc Natl Acad Sci USA 101: 9133-9136, 2004.

6. Kapinya KJ, Löwl D, Fütterer C, Maurer M, Waschke KF, Isaev NK and Dirnagl U: Tolerance against ischemic neuronal injury can be induced by volatile anesthetics and is inducible NO synthase dependent. Stroke 33: 1889-1898, 2002.

7. Ding Q, Wang Q, Deng J, Gu Q, Hu S, Li Y, Su B, Zeng Y and Xiong L: Sevoflurane preconditioning induces rapid ischemic tolerance against spinal cord ischemia/reperfusion through activation of extracellular signal-regulated kinase in rabbits. Anesth Analg 109: 1263-1272, 2009.

8. Westermaier T, Stetter C, Vince GH, Pham M, Tejon JP, Eriskat J, Kunze E, Matthies C, Ernestus RI, Solymosi L and Roosen K: Prophylactic intravenous magnesium sulfate for treatment of aneurysmal subarachnoid hemorrhage: A randomized, placebo-controlled, clinical study. Crit Care Med 38: 1284-1290, 2010.

9. Zheng H, Dong Y, Xu Z, Crosby G, Culley DJ, Zhang Y and Xie Z: Sevoflurane anesthesia in pregnant mice induces neurotoxicity in fetal and offspring mice. Anesthesiology 118: 516-526, 2013.

10. Westermaier T, Zausinger S, Baethmann A and Schmid-Elsaesser R: Dose finding study of intravenous magnesium sulphate in transient focal cerebral ischemia in rats. Acta Neurochir (Wien) 147: 525-532; discussion 532, 2005.

11. Kamibayashi T and Maze M: Clinical uses of alpha2-adrenergic agonists. Anesthesiology 93: 1345-1349, 2000.

12. Jolkkonen J, Puurunen K, Koistinaho J, Kauppinen R, Haapalinna A, Nieminen L and Sivenius J: Neuroprotection by the alpha2-adrenoceptor agonist, dexmedetomidine, in rat focal cerebral ischemia. Eur J Pharmacol 372: 31-36, 1999.

13. Kuhmonen J, Pokorný J, Miettinen R, Haapalinna A, Jolkkonen J, Riekkinen P Sr and Sivenius J: Neuroprotective effects of dexmedetomidine in the gerbil hippocampus after transient global ischemia. Anesthesiology 87: 371-377, 1997.

14. Maier C, Steinberg GK, Sun GH,Zhi GT and Maze M: Neuroprotection by the alpha 2-adrenoreceptor agonist dexmedetomidine in a focal model of cerebral ischemia. Anesthesiology 79: 306-312, 1993.

15. Ibacache M, Sanchez G, Pedrozo Z, Galvez F, Humeres C, Echevarria G, Duaso J, Hassi M, Garcia L, Díaz-Araya G and Lavandero S: Dexmedetomidine preconditioning activates pro-survival kinases and attenuates regional ischemia/reperfusion injury in rat heart. Biochim Biophys Acta 1822: 537-545, 2012. 
16. Wijeysundera DN, Naik JS and Beattie WS: Alpha-2 adrenergic agonists to prevent perioperative cardiovascular complications: A meta-analysis. Am J Med 114: 742-752, 2003.

17. Gu J, Sun P, Zhao H, Watts HR, Sanders RD, Terrando N, Xia P, Maze M and Ma D: Dexmedetomidine provides renoprotection against ischemia-reperfusion injury in mice. Crit Care 15:R153, 2011.

18. Si Y, Bao H, Han L, Shi H, Zhang Y, Xu L, Liu C, Wang J, Yang X, Vohra A and Ma D: Dexmedetomidine protects against renal ischemia and reperfusion injury by inhibiting the JAK/STAT signaling activation. J Transl Med 11: 141, 2013.

19. Zhang XY, Liu ZM, Wen SH, Li YS, Li Y, Yao X, Huang WQ and Liu KX: Dexmedetomidine administration before, but not after, ischemia attenuates intestinal injury induced by intestinal ischemia-reperfusion in rats. Anesthesiology 116: 1035-1046, 2012.

20. Wang ZX, Huang CY, Hua YP, Huang WQ, Deng LH and Liu KX: Dexmedetomidine reduces intestinal and hepatic injury after hepatectomy with inflow occlusion under general anaesthesia: A randomized controlled trial. Br J Anaesth 112: 1055-1064, 2014.
21. Lähdesmäki J, Sallinen J, MacDonald E, Sirviö J and Scheinin M: Alpha2-adrenergic drug effects on brain monoamines, locomotion, and body temperature are largely abolished in mice lacking the alpha2A-adrenoceptor subtype. Neuropharmacology 44: 882-892, 2003.

22. Sallinen J, Link RE, Haapalinna A, Viitamaa T, Kulatunga M, Sjöholm B, Macdonald E, Pelto-Huikko M,Leino T, Barsh GS, et al: Genetic alteration of alpha $2 \mathrm{C}$-adrenoceptor expression in mice: Influence on locomotor, hypothermic, and neurochemical effects of dexmedetomidine, a subtype-nonselective alpha 2-adrenoceptor agonist. Mol Pharmacol 51: 36-46, 1997.

23. Shen ZB, Yin YQ, Tang CP, Yan CY, Chen C and Guo LB: Pharmacodynamic screening and simulation study of anti-hypoxia active fraction of xiangdan injection. J Ethnopharmacol 127: 103-107, 2010.

24. Salmenperä MT, Szlam F and Hug CC Jr: Anesthetic and hemodynamic interactions of dexmedetomidine and fentanyl in dogs. Anesthesiology 80: 837-846, 1994.

25. Hogue CW Jr, Talke P, Stein PK, Richardson C, Domitrovich PP and Sessler DI: Autonomic nervous system responses during sedative infusions of dexmedetomidine. Anesthesiology 97: 592-598, 2002. 